\title{
Enhancing University Research through Corporate Engagement and Collaboration
}

\author{
Jeffrey Scott Vitter, Provost and Executive Vice Chancellor, \\ The University of Kansas \\ Julie S. Nagel, Executive Director of Corporate Partnerships, \\ The University of Kansas
}

The University of Kansas is undergoing a transformation. It is driven by our stra-
tegic plan - aptly named Bold Aspirations - which guides and inspires us to
raise the expectations we have for ourselves, the aspirations we have for our state, and the hopes we have for our world. We are in the third year of Bold Aspirations, and the level of change on campus so far is unprecedented.

Bold Aspirations outlines six important goals for the university. This paper relates specifically to Goal 4 , which is focuses on engaged scholarship: "to engage local, state, national, and global communities as partners in scholarly activities that have direct public impact." As part of that goal, we seek to promote active entrepreneurship and vibrant external partners. A key component of this strategy was the creation of the Office of Corporate Partnerships, developed to diversify KU's research portfolio. The Office of Corporate Partnerships was introduced into KU's existing commercialization enterprise, and in the two years since the office's creation, we have already seen an increase in the amount of corporate and foundation research funding as a percentage of our overall research portfolio.

\section{Creating the Office of Corporate Partnerships}

As background to understand the broader context surrounding the creation of the Office of Corporate Partnerships, KU's historical approach to developing partnerships with businesses was local and ad hoc. The university did not have impressive levels of corporate-funded research. KU's research assets were not organized as efficiently as they should have been to encourage engagement with outside groups.

The KU Center for Technology Commercialization (KUCTC) was established in 2008 as the separate 501(c)3 charged with the management and commercialization of the university's intellectual property - but this activity was its only function. As a glaring example of why such a structure was far from ideal, research agreements with industry sponsors were done by 16 different groups, across KU's two campuses. 
In 2011 we broadened the scope of our commercialization enterprise and began consolidating corporate assets under single umbrella. We created a new position of Associate Vice Chancellor of Innovation and Entrepreneurship to head KUCTC, which strongly signaled our new emphasis on this topic. Later that year, we created the Office of Corporate Partnerships and made it a direct report to the Associate Vice Chancellor of Innovation and Entrepreneurship. We also brought into the fold our technology transfer and faculty startup resources. The idea behind this consolidation was straightforward: By bringing together these previously disparate functions technology transfer, faculty startup formation, and corporate partnerships - we could position ourselves to be more efficient and more flexible in pursuing agreements with industry partners. In fact, we were so committed to the synergies and nimbleness represented by the new organization; we recently changed the name of KUCTC to KU Innovation \& Collaboration (KUIC).

The benefits of this new structure are already apparent. For example, we have created what amounts to a one-stop shop at KU for external groups looking to collaborate with us. Having these groups working under a single set of metrics provides for cross-collaboration. An example is efficiently working out an intellectual property section in an industry-sponsored research agreement that will allow for easy downstream licensing activity. A portal for both faculty and industry sponsors to work through to create researchbased partnerships removes barriers companies often cited as reasons for not working with universities. The net result is that we can more effectively translate KU research to make a real positive difference in people's lives.

Five-year plan for commercialization

When we reorganized our commercialization and entrepreneurship assets in 2011, we assembled a five-year strategic plan with three key goals: 1) to create a national model; 2) to improve our financial performance; and 3) to improve our customer experience, which includes both internal customers (faculty) and external customers (companies.)

To reach these goals, it was clear we needed to create a strategic systems plan. At the time, we did not have systems of record and infrastructure that would allow us to meet those goals. But we did not just want to "catch up" to what other universities were doing. Rather, we aspired to outpace other universities and install new systems in new ways that would leverage each other and enable us to work with companies more easily, while allowing us to make more informed, data-driven decisions on a smaller budget.

\section{How companies partner with KU}

Today, companies can partner with KU in many ways. To put it another way, KU has many different products (or domains) that companies may want to access. These products include faculty expertise, lab capabilities, student talent, workforce development opportunities, technology licensing, and of course philanthropy, which entails sponsoring scholarships, professorships, and other university needs. Some companies just need one of these KU products. Other 
companies may want to interact with $\mathrm{KU}$ in a number of domains. More significantly, interactions between $\mathrm{KU}$ and a company can lead to other forms of partnership with the company, which can move the company along a conceptual path of increasing engagement, as indicated in the figure below:
The Office of Corporate Partnerships is based upon that comprehensive philosophy. We facilitate all aspects of industry-sponsored research at our core, and we lead the university-wide strategy on how to coordinate these different areas with a central message. Yes, we like to have many boots on the ground and

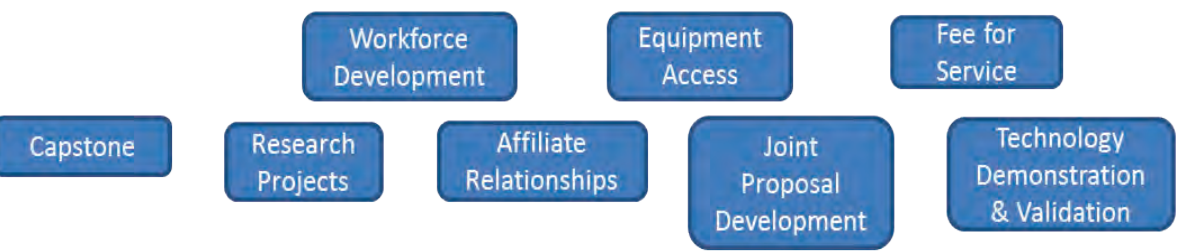

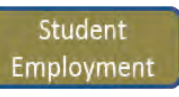

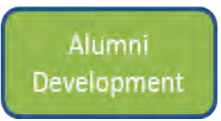

There are several groups across campus that are involved in these various products that make up KU's portfolio. But today, they all come together under the umbrella of the Office of Corporate Partnerships to ensure they work together in an efficient and integrated manner. It does not concern us how a company wants to partner with the university; what matters is that the company does want to partner with us in some way. Because of the Office of Corporate Partnerships, when a company approaches us with a need or idea, we can now expose the company to the entire menu of KU resources - resources the company might not have even known about prior to contacting KU. For example, under our current system, it would not be unusual for a company to approach KU to explore the capability of a specific laboratory, yet end up investing in KU via a sponsored research engagement as well. many ongoing conversations with companies. But at the same time, we want all that communication done in a coordinated and traceable way so that KU staff in different units know what their colleagues are doing and saying. Thus, it is crucial for us to share information about company visits and interactions and to put forward a highly coordinated face to companies. By so doing, we know exactly how the company has worked with the university in the past, which helps us expand the collaboration in the future. By sharing, each of the different groups that works with companies can leverage the others and create a greater benefit for the university.

\section{Building our team}

We continue to build out the Office of Corporate Partnerships utilizing a distributive model for company engagement. As part of this model, we have jointly funded staff positions in a number of our key schools - business and engineering, for example - enabling us to 
have deep knowledge of the research and priorities within those schools.

While school-specific or subject-specific expertise is important, companies often have broader interdisciplinary needs. An understanding of those broader needs is why it is so important for our schoolspecific staff to work together and communicate with the representatives from the other schools and units. Additionally, these individuals act as liaisons with the industry agreements group. They still serve as the single KU face for the company, but in addition, they conceptually have the industry agreements group and the tech transfer group behind them supporting that transaction. This model has proven successful at building more partnerships within the academic units.

\section{Industry portal}

When the Office of Corporate Partnerships was established, it was obvious that our external customers - our company collaborators - needed an easy way to work with KU. We did not want KU to be a "black box" in which partners had to come to the table and then struggle to figure out our university. We wanted to make it easy for companies to access the products we offer. Thus, we created an "industry portal": a single entry point for potential company partners to access the specific things they wanted at the university. We have a website that supports this function as well. The different products that companies want to access are organized in this central location.

Earlier in this article, we discussed the industry agreements group. It too is a key part of the industry portal. A research focused collaboration typically requires negotiation of one or more legal agreements to enable the collaborative work. An effective approach has been for the industry agreements group to handle the negotiation of those contracts as a single entry point for all of KU. The number of agreements we have done through the industry portal continues to increase, while our negotiation time continues to decrease. We track these two metrics on a monthly basis.

One of the great strengths of the new structure is that our industry agreements group liaises with the licensing associates in the technology transfer group. The industry agreements team negotiating the contract understands the priorities and goals of the Office of Corporate Partnerships. As a result, we can ensure that IP language favors downstream licensing so that there are no surprises on the backend. This approach has allowed us to be more efficient and strategic in the execution of research agreements with company sponsors.

Technology and a common tracking system

As previously mentioned, one immediate success was the tracking system that we put into place for the Office of Corporate Partnerships as part of the overall strategic systems mission.

Prior to the installation of the tracking system, we relied solely on monthly meetings to share information on corporate engagement. As one might imagine, monthly meetings were not an especially efficient or comprehensive way of sharing the hundreds - or thousands - of different corporate touches made by faculty and staff across the university.

Consequently, we envisioned a customer relationship management (CRM) 
system, which is a best practice employed in the corporate world to track all sorts of data, especially in sales. We opted to use Salesforce.com and configured it to track all our company engagements. Today, we have data feeds coming in from numerous units across multiple campuses. These data feeds include details on tech transfer, development, research, and numerous other ways in which companies engage with KU.

The CRM tool functions as a system of record for the Office of Corporate Partnerships. The system allows us to track all industry engagement data that previously had been scattered across different systems. Additionally, we went back and loaded data from the previous five years. This tool now allows the Office of Corporate Partnerships to track all company meetings and to build institutional knowledge about company partners. The system is also available to the internal stakeholders who contribute to the system, using the following general principle: "if you give data to the system, you get a seat at the table." These internal stakeholders can log into the system, do reporting, and see activity just as Office of Corporate Partnerships staff can.

Additionally, the CRM has become a strong prospecting tool for different divisions across KU that work with companies. For example, the CRM allows the Office of Corporate Partnerships to identify company partners that have teamed with KU in some capacity but perhaps not on research. For technology transfer, the CRM enables more efficiently marketing of KU technologies available for license by identifying new company pro- spects. Our Career Services staff members use it to prospect new companies to engage in career fairs. In addition, our Endowment team uses it to get background on new philanthropic target companies.

\section{Using data from the CRM}

Having that much data in one place really empowers us to dig in, do some robust reporting and analysis, and find new ways to do business.

For example, we have configured a 360-degree report showing all the interactions any given company has with $\mathrm{KU}$ in a single one-page report output. The report includes market information about the company and areas in which KU excels that might be useful to the company. These reports are used by deans, faculty, senior administration, and other KU officials as intelligence prior to meeting with a new potential company partner.

Another application we have added is data.com, a tool that provides us contacts from any company in our database.

We also have developed partnership reports, which enable us to understand KU's portfolio of partner companies. We define a partner as a company engaged in at least three broad categories across KU, such as tech transfer, career services, development, or research. By this definition, KU currently has more than 80 companies as partners. With our new tools, we are now digging deeper to discover how we can weigh individual partnerships differently. For example, a monetized partnership will be weighted more heavily than a non-monetized interaction, allowing us to further narrow the portfolio. 
Another interesting thing we saw coming out of the CRM was how other groups within KU's commercialization unit have been able to leverage the data. For example, one of the primary functions of our tech transfer group is to market KU intellectual property for licensing. But prior to 2011, the group really did not have specific targets or vehicles to get the right information to those targets. Sure, they had some database tools with market information, but the processes were not targeted and efficient. However, things changed when the CRM came online. Suddenly our tech transfer group could easily run reports within the system on all companies that already had engagements with KU. The tech transfer group can narrow companies that are in the same industry sector as the technology they are marketing using Standard Industry Classification (SIC) codes or North American Industry Classification System (NAICS) codes. They now have an instant list of leads to market the technology, and they then use data.com to pull the contacts. The total package allows them to market technologies at a must faster rate, which we expect will lead to more licenses executed annually.

It's working ... and we are developing more infrastructure

Our efforts are already bearing fruit, as evidenced by our core metrics. Between Fiscal Year 2011 and 2013, our licensing revenue increased by a multiple of 15 , or by a multiple of four if you exclude an outlier that generated significant revenue to KU. Licensing agreements increased by 15 percent, patent issues increased by 131 percent, and industrysponsored research is up 40 percent.
And we are not stopping there. We have more infrastructure improvements in mind that we think will further leverage what we have already put into place. We have gathered requirements for a faculty expertise search functionality that would leverage KU's implementation of Professional Record Online (PRO) system where all faculty $\mathrm{CV}$ data are held electronically. Our vision for this tool is to be able to research scholarly and research activity of all faculty - not limited just to STEM faculty, as many search expertise functionalities are limited at other universities. We think companies would find such a system very helpful in locating research experts at KU in particular areas where they have a need. Additionally, we anticipate a benefit for our faculty by promoting multidisciplinary team formation, and it will help our students find faculty mentors and labs that meet their interests. Other external organizations and media outlets could also use this tool. The tool could also be benefit our local economic development partners, who could use it to help recruit prospective companies to the area.

An interesting possibility is to combine the intelligence from our faculty expertise search tool with the company leads provided by the CRM. For example, we can make use of a search expertise functionality that can easily search faculty from a research or creative activity standpoint. We also have cataloged all the companies that work with $\mathrm{KU}$, and they are all classified and searchable by SIC and NAICS codes. How can we best tie these two capabilities together? One of the roles of our KUIC staff is to align industry needs with KU capabilities. Can 
we perform that matchmaking more effectively with semi-automated tools? That challenge is next on our agenda: to join the database that holds our faculty expertise with our CRM by industry sector in order to visualize the end result. We continue to envision how we can use these systems more creatively in order to get better results and with fewer staff resources.

\section{Onward and upward}

The University of Kansas has come a long way in the past two years. Moving forward, under the umbrella of the Office of Corporate Partnerships, we will continue to find new opportunities to engage with industry partners in ways that mutually benefit the university, our state, and society overall.

Acknowledgements. We thank Joe Monaco and Gavin Young in the KU Office of Public Affairs for their support in translating our presentation into article form and Tricia Bergman in the Office of Corporate Partnerships for the development of the figure. 